\title{
LOCALIZED PIGMENTED VILLONODULAR SYNOVITIS: CASE REPORT
}

Fabiola Andrea de Carvalho Godoy', Carlos Alberto Cury Faustino², Cláudio Santos Meneses ${ }^{3}$, Sergio Tadao Nishi ${ }^{4}$, César Eduardo Giancoli Góes ${ }^{4}$, Abaeté Leite do Canto 3

\section{ABSTRACT}

This case concerned a female patient with a complaint of pain in the anterior region of her left knee during and after sports activities, followed by joint blockage three months ago. From imaging examinations, simple radiography of the knee was normal and magnetic resonance showed a solid expansive mass, possibly corresponding to soft-tissue chondroma or focal nodular synovitis.
Arthroscopic resection of the lesion was performed, and the diagnosis of diffuse giant cell tumor resembling localized pigmented villonodular synovitis (PVNS) was made from the result of the anatomopathological examination. The patient presented good clinical evolution, with disappearance of symptoms and return to physical activities.

Keywords - Synovitis, Pigmented Villonodular; Arthroscopy; Knee; Giant cell tumor

\section{INTRODUCTION}

Intra-articular giant cell tumor or localized pigmented villonodular synovitis (PVNS) is a rare lesion. Moreover, the nomenclature used by pathologists or even by some other authors tends to lead to diagnostic doubts.

In 1852, Chassaignac ${ }^{(1)}$ was the first to describe a nodular lesion that originated in the flexor tendon sheaths of the fingers. In 1864, Simon ${ }^{(2)}$ described the localized form of the disease in the knee, and in 1909 , Moser $^{(3)}$ described the diffuse form of the disease. In 1941 , Jaffe et $\mathrm{al}^{(4)}$ proposed the term pigmented villonodular synovitis for these manifestations.

The nomenclature used today is as described by Granowitz et $\mathrm{al}^{(5)}$, in which the term pigmented villonodular synovitis is used for intra-articular findings; pigmented villonodular bursitis is used for localized lesions in bursas; and pigmented villonodular tenosynovitis is used for lesions originating from the tendon sheath, also known as giant cell tumors of the tendon sheath. Pigmented villonodular synovitis is divided into the diffuse form and the localized form.

The nomenclature used by pathologists or in scientific articles can often be confusing. The use of synonyms such as intra-articular giant cell tumor or giant cell-like tumor causes confusion among non-specialist physicians and patients.

Villonodular synovitis may be diffuse or localized, and the etiology remains uncertain. It is observed in most of the cases among patients between 20 and 50 years of age, with slightly higher prevalence among females ${ }^{(4,6)}$.

The treatment is based on resection of the lesion by means of arthroscopy and/or open surgery, with a local recurrence rate of 18 to $46 \%{ }^{(7,8)}$.

1 - Trainee Physician in the Knee Group, Orthoservice Hospital, São José dos Campos, São Paulo, Brazil.

2 - Physician responsible for the Knee Surgery Group, Orthoservice Hospital, São José dos Campos, São Paulo, Brazil.

3 - Pathologist at Cipax Laboratory, São José dos Campos, São Paulo, Brazil.

4 - Physician in the Knee Group, Orthoservice Hospital, São José dos Campos, São Paulo, Brazil.

Work performed at Orthoservice Hospital, São José dos Campos, São Paulo.

Correspondence: Avenida Tívoli, 433, Vila Bethânia - 12245-230 - São José dos Campos, SP - E-mail: fabiolacgodoy@globo.com

Work received for publication: June 13, 2010; accepted for publication: February 15, 2011.

The authors declare that there was no conflict of interest in conducting this work 


\section{CLINICAL CASE}

The patient was a 37-year-old white female small trader who had presented pain in the anterior region of her left knee during and after sports activities, followed by joint blockage over the three-month period prior to examination. Orthopedic physical examination showed good alignment of the lower limbs, absence of edema or joint effusion and muscle atrophy in the vastus medialis obliquus. She presented pain on compression of the femoropatellar joint, with negative meniscal and ligament tests, and absence of signs of joint instability. Her range of motion was complete and free from pain. There were no other signs or symptoms and her personal and family histories were unremarkable. Imaging examinations were performed: simple radiography of the left knee in frontal, lateral and axial views, with normal results (Figure 1 and Figure 2); and magnetic resonance imaging (Figures 3 and Figure 4). The latter showed intra-substance degenerative abnormalities in the posterior cornua of the medial and lateral menisci, and solid expansive formation of pre-femoral fat, which could correspond to soft-tissue chondroma or focal nodular synovitis.

The patient underwent arthroscopy (Figure 5 and Figure 6) in the left knee, with marginal resection of the lesion. The resected material was sent for anatomopathological examination. The anatomopathological report (Figure 7 and Figure 8) showed that

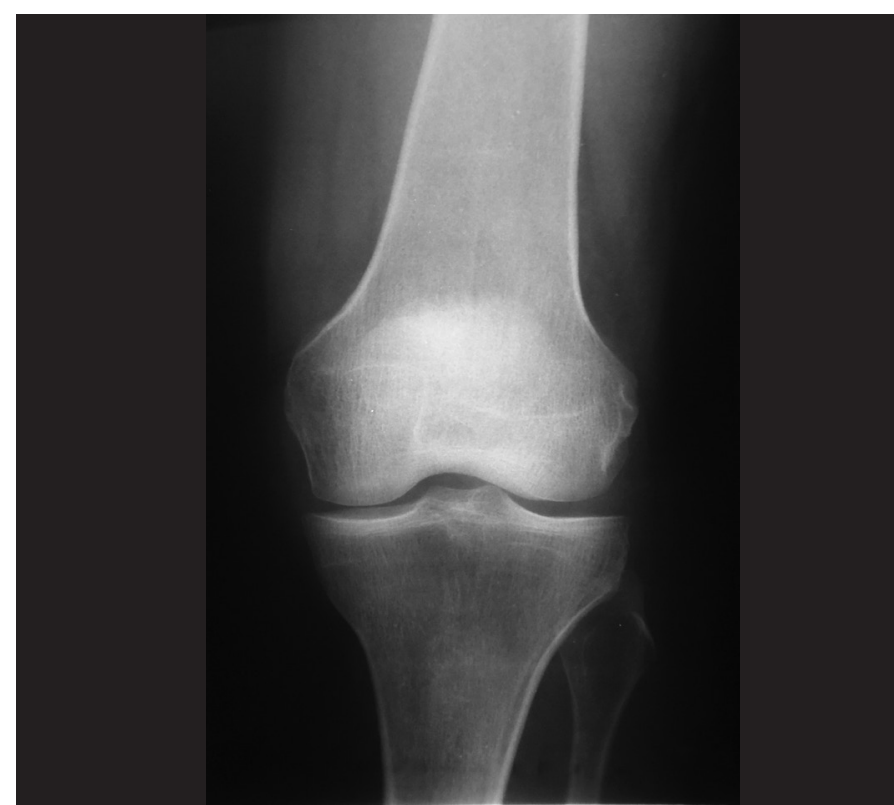

Figure 1- Radiograph on the left knee, in frontal view: normal results. this was a well-circumscribed neoplasm consisting of diffusely distributed epithelioid cells interspersed with dense connective tissue/giant cell-like tumor. Immunohistochemical analysis showed that the neoplasm had the profile of giant cell-like tumor/pigmented villonodular synovitis.

On the first postoperative day, the patient was already asymptomatic. Thirty days after surgery, she was released to perform all her activities. She will be followed up with magnetic resonance imaging every six months over the first year and then annually for two years.

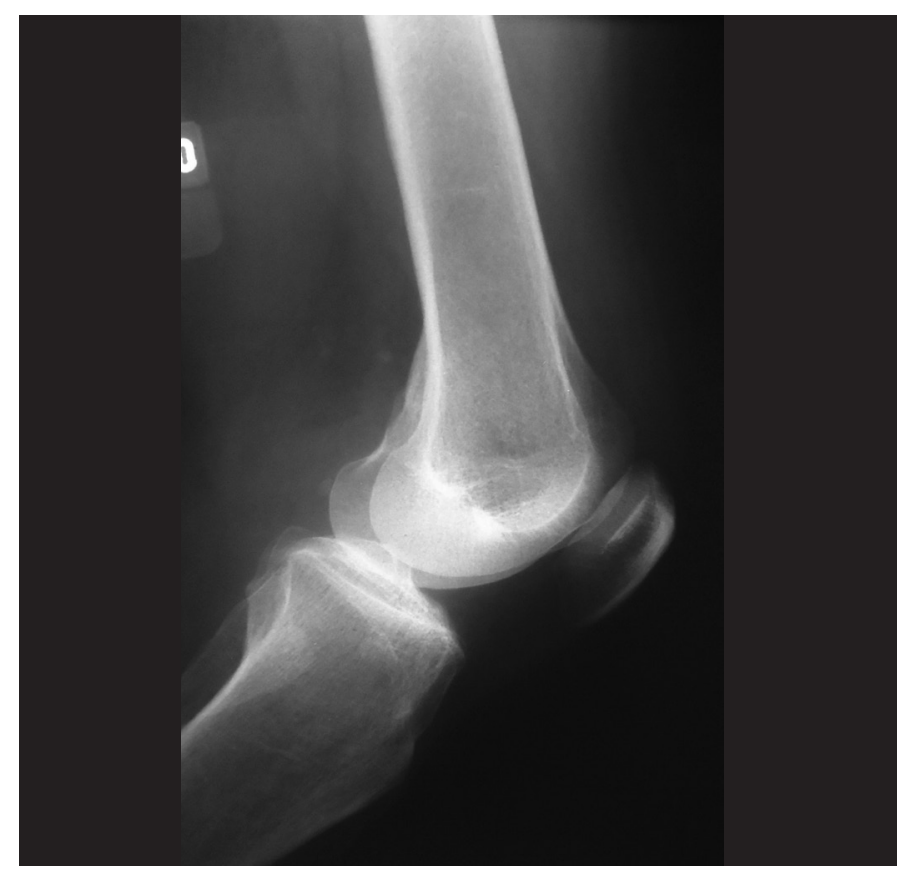

Figure 2 - Radiograph on the left knee, in lateral view: normal results.

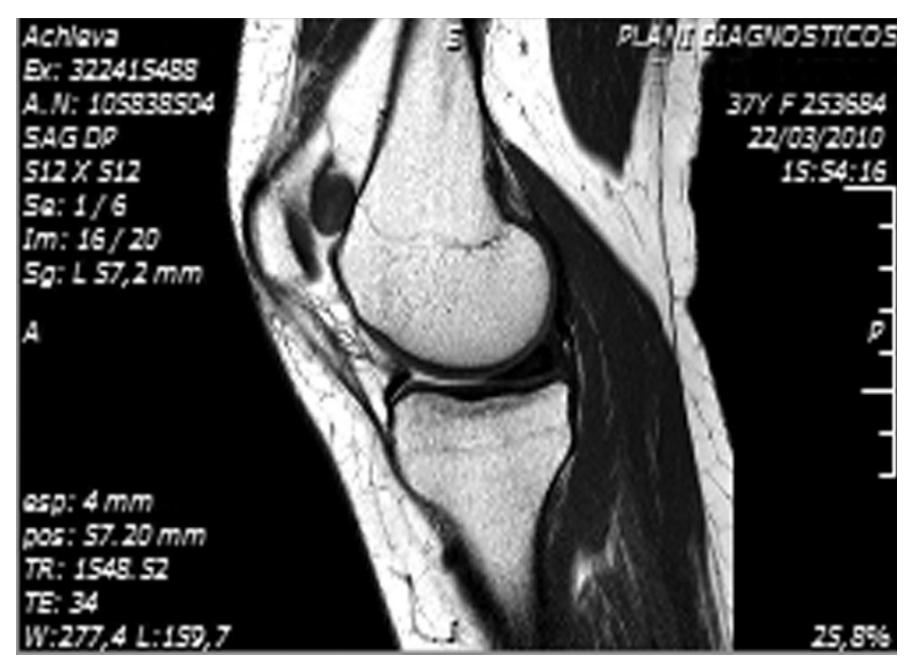

Figure 3 - Sagittal T1-weighted magnetic resonance image showing nodulation in the retropatellar region. 


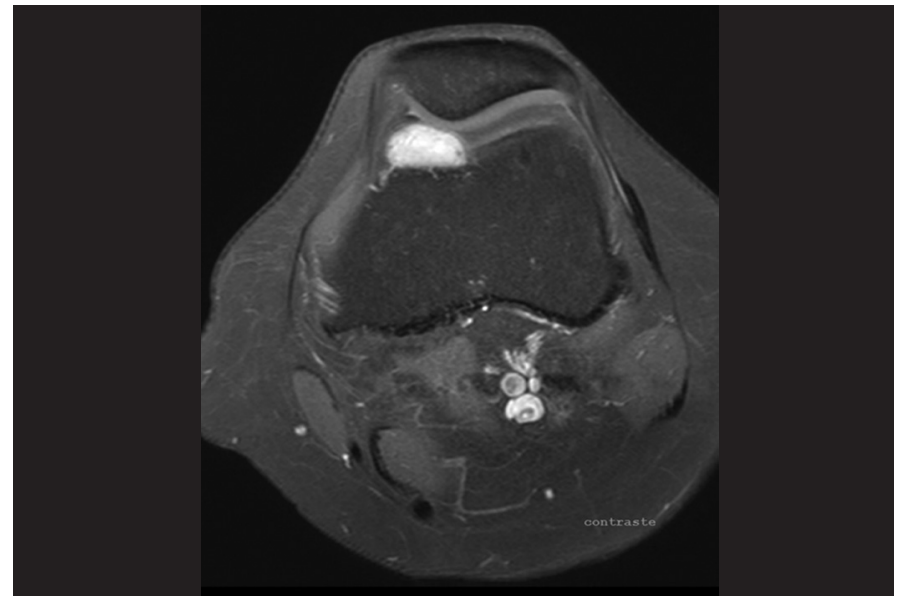

Figure 4 - Axial T2-weighted magnetic resonance image with contrast, showing nodulation in the retropatellar region.
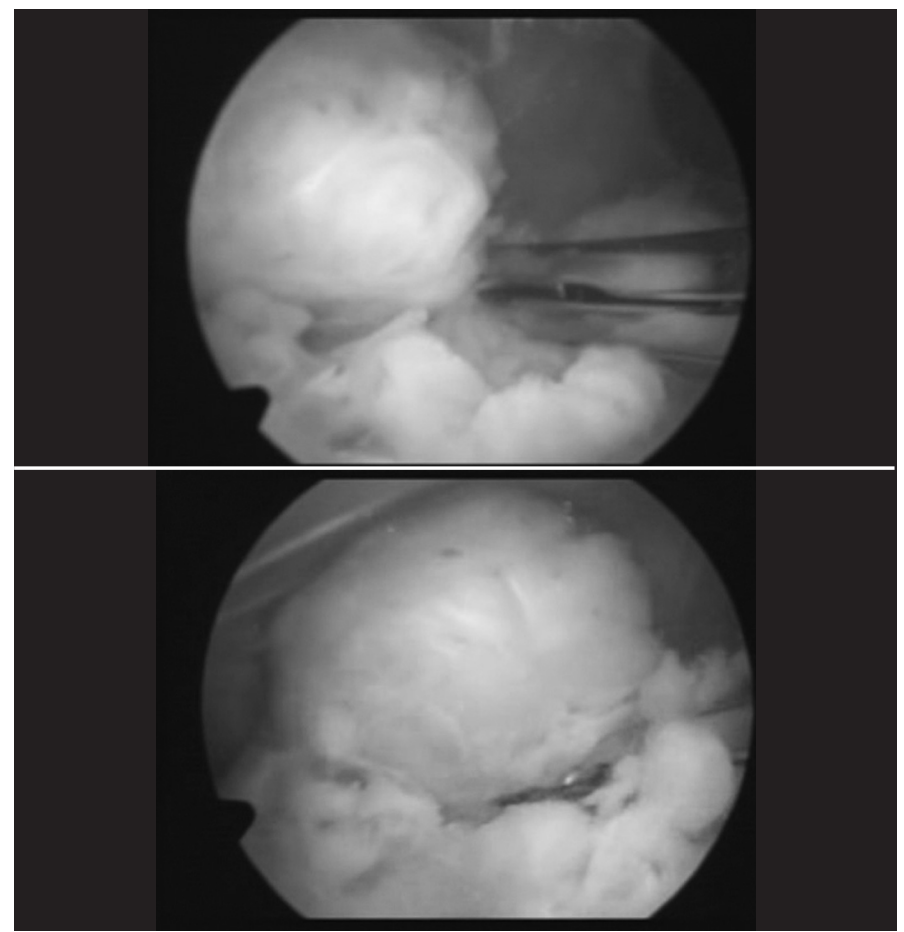

Figures 5 and $\mathbf{6}$ - Arthroscopic resection of the lesion.

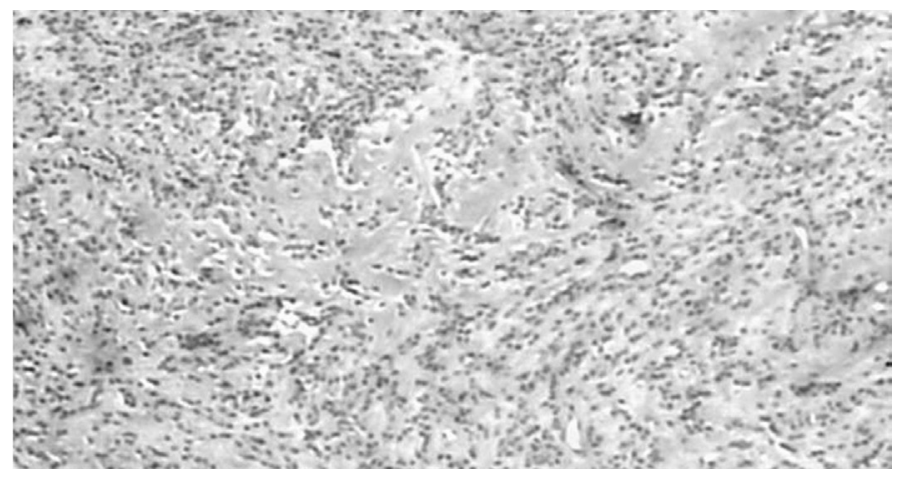

Figure 7 - Slide stained with hematoxylin-eosin, showing proliferation of diffusely distributed epithelioid cells interspersed with dense connective tissue. Macrophages with hemosiderin accumulations in the cytoplasm and multinucleated giant cells can be seen.

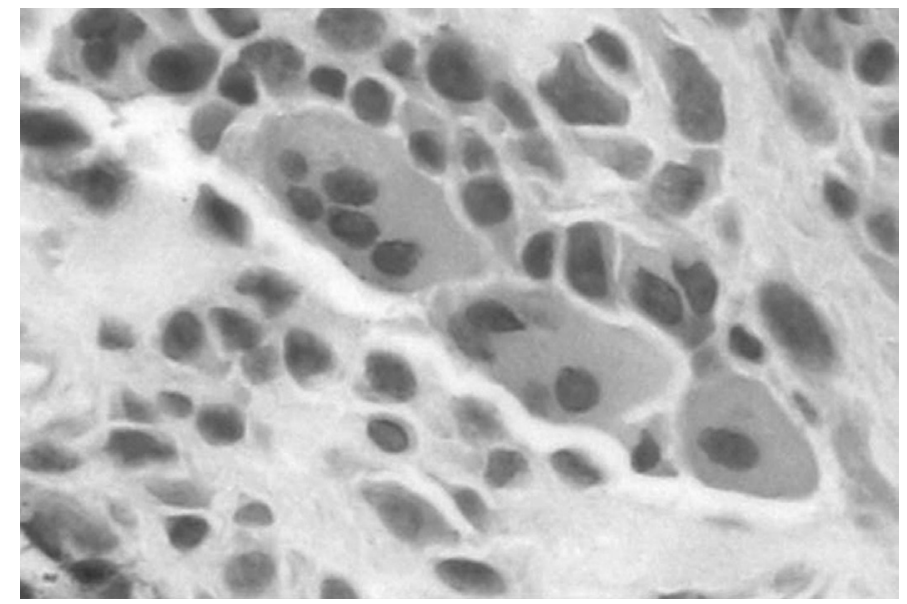

Figure 8 - Detail of a multinucleated giant cell.

\section{DISCUSSION}

Pigmented villonodular synovitis comprises a group of pathological conditions with similar anatomopathological characteristics. PVNS is a rare disease with 1.8 new cases per year, per million individuals ${ }^{(9)}$. The nomenclature of the disease that is sometimes used in pathology reports or scientific studies is often confusing and leads to doubtful diagnoses.

We observed that some published studies have described the lesion as synovial giant cell tumor, while others have described it as localized pigmented villonodular synovitis, not knowing whether the lesion is intra-synovial or from the tendon sheath ${ }^{(10)}$. The nomenclature proposed by Granowitz et al ${ }^{(5)}$ determines that the term pigmented villonodular synovitis should be used for intra-articular findings; pigmented villonodular bursitis for lesions that are localized in bursas; and pigmented villonodular tenosynovitis for lesions originating from the tendon sheath, also known as giant cell tumors of the tendon sheath.

Pigmented villonodular synovitis is a rare disease, but it involves the knee in $80 \%$ of the cases. The intra-articular disease may be localized or diffuse. PVNS is characterized by hyperplasia of the synovium or tendon sheath, with notable proliferation of stromal cells, large quantities of intra and extracellular hemosiderin and multinucleated giant cells. The disease is most prevalent in patients between the ages of 20 and 50 years, with slight predominance among females ${ }^{(11)}$.

The etiology has not been established, but it may be associated with repeated hemarthrosis. Other possibilities suggested in the literature include: benign 
neoplastic processes, reactions to unknown stimuli and reactions to repeated episodes of trauma ${ }^{(7,12)}$.

The symptoms are progressive. Pain, repeated non-traumatic joint effusion and limitation of joint range of motion are observed in the diffuse form. The localized form is difficult to diagnose, since the symptoms may mimic meniscal lesions or intra-articular free bodies, and complaints of abnormal mobility ${ }^{(7,13)}$. In the physical examination, the findings are nonspecific: patients may be oligosymptomatic, like in the case presented here, or they may present local heat, joint effusion, diminished range of motion, pain, muscle atrophy and a palpable mass. Meniscal or ligament abnormalities are generally not found. Because of the difficulties in making a conclusive clinical diagnosis, complementary imaging examinations are necessary ${ }^{(7,12,13)}$.

The important complementary examinations are simple radiography and magnetic resonance imaging. In cases at the initial stage, simple radiography generally shows normal results, although there may be erosion with a periosteal reaction in regions without loading. In chronic cases, mirror-image erosive lesions are found in the affected joint ${ }^{(14)}$.

Magnetic resonance imaging is an important examination for establishing the diagnostic hypothesis and directing the treatment. Areas of low signal are observed with T1 and T2 weighting in the synovial membrane ${ }^{(14)}$. In PVNS, the synovial membrane is irregular, and joint effusion is frequently seen.

The histological findings show that these lesions are well differentiated, with destructive proliferation of synovial-like mononuclear cells, in association with multinucleated giant cells, xanthomized macrophages, hemosiderophages and inflammatory cells ${ }^{(8,15)}$.

PVNS is a benign lesion. A potential for malignant degeneration has been reported, but is extremely rare $^{(8)}$.

The recommended treatment for PVNS is resection of the lesion. Synovectomy by means of multiple-portal arthroscopy is the treatment of choice. A posterior open access may be necessary in patients with extension of the disease to the posterior and extracapsular regions ${ }^{(7,12,16)}$. Arthroscopic resection is the method most indicated for treating PVNS. Arthroscopy causes less injury to the structures of the knee and leads to earlier recovery ${ }^{(7,12)}$. Radiotherapy is used in cases of multiple recurrence ${ }^{(17,18,19)}$.

Patients are followed up by means of periodic magnetic resonance imaging, every six to twelve months. The prognosis is good, but local recurrence occurs in 12 to $48 \%$ of the cases ${ }^{(5,10)}$.

\section{REFERENCES}

1. Chassaignac M. Cancer de la gaine des tendons. Gaz Hosp Civ Milit. 1852;47:185-6.

2. Simon G. Extirpation einr serh grossen, mit dickem stiele angewachsenen kniegelenkmaus mit glucklichem erfolge. Arch Klinn Chir. 1864;6:573-6.

3. Moser E. Primares sarkom der fussgelenklapsel. Extirpation. Dauerheiung Dtsch Z Chir. 1909;98:306-10.

4. Jaffe HL, Lichtenstein L, Sutro CJ. Pigmented villonodular synovitis, bursitis and tenosynovitis. A discussion of synovial and bursal equivalents of the tenosynovial lesion commonly denoted as xanthorna, xanthogranuloma, giant cell tumor or myeloplaxoma of the tendon sheath, with some consideration of this tendon sheath lesion itself. Arch Pathol.1941;31:731-65.

5. Granowitz SP, D'Antonio J, Mankin HL. The pathogenesis and long-term end results of pigmented villonodular synovitis. Clin Orthop Relat Res. 1976;(114):335-51

6. Ghadially FN, Lalonde JM, Dick CE. Ultrastructure of pigmented villonodular synovitis. J Pathol. 1979;127(1):19-26.

7. Kim SJ, Shin SJ, Choi NH, Choo ET. Arthroscopic treatment for localized pigmented villonodular synovitis of the knee. Clin Orthop Relat Res. 2000;(379):224-30.

8. Oda Y, Takahira T, Yokoyama R, Tsuneyoshi M. Diffuse-type giant cell tumor/ pigmented villonodular synovitis arising in the sacrum: malignant form. Pathol Int. 2007;57(9):627-31.

9. Ushijima M, Hashimoto H, Tsuneyoshi M, Enjoji M. Pigmented villonodular synovitis. A clinicopathologic study of 52 cases. Acta Pathol Jpn. 1986;36(3):317-26.
10. Abdalla JR, Cohen M, Nóbrega J, Forgas A. Tumor gigantocelular sinovial do joelho. Rev Bras Ortop. 2009;44(5):437-49.

11. Garner HH, Ortiguera CJ, Nakhlen RE. Pigmented villonodular synovitis. Radiographics. 2008;28(5):1519-23.

12. Ogilvie-harris DJ, Mclean J, Zarnett ME. Pigmented villonodular synovitis of the knee, and arthoscopic local excision. J Bone Joint Surg Am. 1992;74(6): 952.

13. Aşik M, Erlap L, Altinel L, Cetik O. Localized pigmented villonodular synovitis of the knee. Arthroscopy. 2001;17(6):E23.

14. Goldman AB, DiCarlo EF. Pigmented villonodular synovitis. Diagnosis and differential diagnosis. Radiol Clin North Am. 1988;26(6):1327-47.

15. Soma P, Loreto F, Galia A, Siragó P. Diffuse-type giant cell tumor. Plast Reconstr Surg. 2006;117(5):1664-5.

16. Zvijac JE, Lau AC, Hechtman KS, Uribe JW, Tjin-A-Tsoi EW. Arthroscopic treatment of pigmented villonodular synovitis of the knee. Arthroscopy. 1999;15(6):613-7.

17. O'Sullivan B, Cummings B, Catton C, Bell R, Davis A, Fornasier V, Goldberg R. Outcome following radiation treatment for high-risk pigmented villonodular synovitis. Int J Radiat Oncol Biol Phys. 1995;32(3):777-86.

18. Blanco CE, Leon HO, Guthrie TB. Combined partial arthroscopic synovectomy and radiation therapy for diffuse pigmented villonodular synovitis of the knee. Arthroscopy. 2001;17(5):527-31.

19. Chin KR, Barr SJ, Winalski C, Zurakowski D, Brick GW. Treatment of advanced primary and recurrent diffuse pigmented villonodular synovitis of the knee. J Bone Joint Surg Am. 2002;84(12):2192-202. 